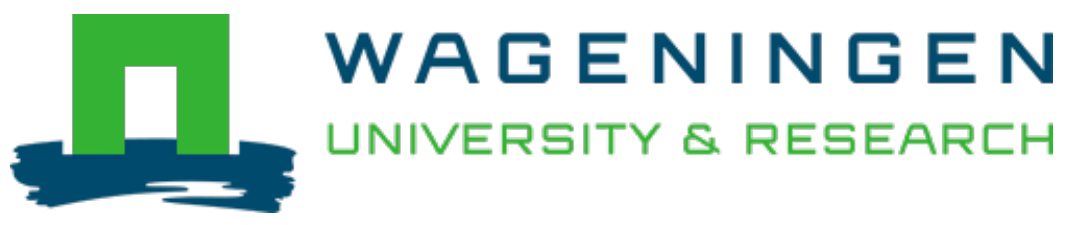

\title{
Mediation of emotional and external eating between dieting and food intake or BMI gain in women
}

\author{
Appetite \\ Strien, Tatjana; Konttinen, Hanna M.; Ouwens, Machteld A.; Laar, Floris A.; Winkens, Laura H.H. \\ https://doi.org/10.1016/j.appet.2019.104493
}

This article is made publicly available in the institutional repository of Wageningen University and Research, under the terms of article $25 \mathrm{fa}$ of the Dutch Copyright Act, also known as the Amendment Taverne. This has been done with explicit consent by the author.

Article 25 fa states that the author of a short scientific work funded either wholly or partially by Dutch public funds is entitled to make that work publicly available for no consideration following a reasonable period of time after the work was first published, provided that clear reference is made to the source of the first publication of the work.

This publication is distributed under The Association of Universities in the Netherlands (VSNU) 'Article $25 \mathrm{fa}$ implementation' project. In this project research outputs of researchers employed by Dutch Universities that comply with the legal requirements of Article $25 \mathrm{fa}$ of the Dutch Copyright Act are distributed online and free of cost or other barriers in institutional repositories. Research outputs are distributed six months after their first online publication in the original published version and with proper attribution to the source of the original publication.

You are permitted to download and use the publication for personal purposes. All rights remain with the author(s) and / or copyright owner(s) of this work. Any use of the publication or parts of it other than authorised under article $25 \mathrm{fa}$ of the Dutch Copyright act is prohibited. Wageningen University \& Research and the author(s) of this publication shall not be held responsible or liable for any damages resulting from your (re)use of this publication.

For questions regarding the public availability of this article please contact openscience.library@,wur.nl 


\title{
Mediation of emotional and external eating between dieting and food intake or BMI gain in women
}

\author{
Tatjana van Strien ${ }^{\mathrm{a}, \mathrm{b}, *}$, Hanna M. Konttinen ${ }^{\mathrm{c}}$, Machteld A. Ouwens ${ }^{\mathrm{d}}$, Floris A. van de Laar ${ }^{\mathrm{e}}$, \\ Laura H.H. Winkens ${ }^{\mathrm{f}}$ \\ a Behavioural Science Institute, Radboud University Nijmegen, Nijmegen, the Netherlands \\ ${ }^{\mathrm{b}}$ Department of Health Sciences, Faculty of Science, Vrije Universiteit Amsterdam, Public Health Research Institute, Amsterdam, the Netherlands \\ ${ }^{\mathrm{c}}$ Department of Social Research, University of Helsinki, Helsinki, Finland \\ ${ }^{\mathrm{d}}$ GGzBreburg, PersonaCura, Tilburg, the Netherlands and Tranzo, Tilburg University, the Netherlands \\ ${ }^{\mathrm{e}}$ Department of Primary and Community Care, Radboud University Nijmegen Medical Centre, Nijmegen, the Netherlands \\ ${ }^{\mathrm{f}}$ Consumption and Healthy Lifestyles Chair Group, Wageningen University \& Research, Wageningen, the Netherlands
}

\section{A R T I C L E I N F O}

\section{Keywords:}

Dieting

Weight gain

Emotional eating

External eating

(Serial) mediation

Women

\begin{abstract}
A B S T R A C T
Objective: Dieting to control body weight is often associated with weight gain, particularly so in women; however, the underlying mechanisms are unclear. In a series of studies on women, we examined whether the relationship between dieting and weight gain can be explained by (serial) mediation of emotional eating (EE) and/or subsequent external eating (EX).

Methods: In a pilot study (116 women), we first assessed this (serial) mediation between dieting or dietary restraint and actual food consumption in the laboratory. In Study 1, a four-year follow up on patients with newly diagnosed type 2 diabetes (51 women), we assessed this (serial) mediation between dietary restraint and change in BMI and intake of energy (Kcal; Food Frequency Questionnaire). In Study 2, a three-year follow up study in a representative Dutch sample (287 women), we assessed this (serial) mediation between dieting and change in BMI.

Results: There was consistent support for (serial) mediation: In the pilot study, frequency of dieting and dietary restraint were both indirectly associated with grams of crackers eaten through EE and EX. In study 1, dietary restraint had a significant $(95 \% \mathrm{CI})$ indirect association with subsequent change in measured BMI and a marginally (90\% CI) significant indirect association with intake of energy through EE and EX. In study 2, EE marginally $(90 \% \mathrm{CI})$ acted as a mediator between frequency of dieting and subsequent self-reported change in BMI. In the subsample of overweight women $(n=146)$ frequency of dieting was indirectly associated with subsequent self-reported change in BMI through EE and EX.

Conclusion: The possibility that female dieters may gain weight through EE and/or subsequent EX should be taken into account when treating women with overweight or obesity.
\end{abstract}

\section{Introduction}

Calorie-restricted diets are notoriously ineffective beyond the short term for patients with overweight. In the long term, most of the lost body weight is regained, with some patients even ending up weighing more than before the diet (Langeveld \& DeVries, 2015; Mann et al., 2007). Also, self-reported dieting to lose body weight has repeatedly predicted future weight gain in longitudinal population studies (e.g., Chaput et al., 2009; Sares-Jäske et al., 2019; Siahpush et al., 2015). Though studies on the possible moderating effect of sex on the association between dieting and subsequent weight change have been scarce, there is evidence that dieting is associated with weight gain in women but not in men (e.g., Drapeau et al., 2003; Field et al., 2007; Klesges, Isbell, \& Klesges, 1992; Korkeila, Rissanen, Kaprio, Sørensen, \& Koskenvuo, 1999; Van Strien, Herman \& Verheijden, 2014). The present study aimed to explain the weight gain of female dieters by assessing possible underlying mechanisms (mediators) between dieting and weight gain. As will be elaborated below, tested mediators are emotional eating, i.e. the tendency to eat in response to negative emotions (Van Strien, Donker and Ouwens, 2016) and external eating, i.e.

\footnotetext{
* Corresponding author. Behavioural Science Institute, Radboud University Nijmegen, P.O. Box 9104, 6500 HE, Nijmegen, the Netherlands.

E-mail addresses: t.vanstrien@psych.ru.nl (T. van Strien), hanna.konttinen@helsinki.fi (H.M. Konttinen), machteldouwens@gmail.com (M.A. Ouwens), Floris.vandeLaar@radboudumc.nl (F.A. van de Laar), laura.winkens@wur.nl (L.H.H. Winkens).
} 
the tendency to eat in response to food-related cues such as the smell or taste of food (Rodin, 1981). ${ }^{1}$ The results may provide insight into treatment strategies for women who are overweight or obese.

The weight regain of dieters has been explained by the possibility that the body cannot distinguish food shortage from self-imposed food restriction and acts as if in starvation mode: metabolic rate is slowed down (anabolism) and hunger and appetite are increased (Goldsmith et al., 2010). Negative emotions may undermine the self-control of dieters in regard to their restriction of food intake. Indeed, after induction of stress or negative emotions, dieters showed in various experiments higher food intake compared to non-dieters (e.g. Heatherton, Herman, \& Polivy, 1991; Herman \& Polivy, 1975). Dieting is therefore considered a risk factor for an enhanced tendency towards emotional eating (Herman \& Polivy, 1980; Van Strien et al., 1986), possibly because dieting can be a stressor (Nakamura, Walker, \& Ikuta, 2016) and stress may be associated with emotional eating (Almajwal, 2016). A further consequence of the continuous struggle of dieters against their hunger sensations may be that they altogether lose contact with their feelings of hunger and satiety which may be an additional risk factor for emotional eating. The tendency to eat in response to negative emotions or stress is considered an a-typical stress response, the typical stress response being not eating because the physiological stress reactions mimic the internal sensations associated with feeding induced satiety (Gold \& Chrousos, 2002). Emotional eating, in turn, has in several studies been shown to be associated with weight gain (see the review by Frayn \& Knäuper, 2018). Taken together: emotional eating could act as a mediator between dieting and weight gain: dieting $\rightarrow$ emotional eating $\rightarrow$ weight gain.

It is also possible that the association between dieting and weight gain is serially mediated-a type of mediation that assumes a causal chain linking several mediators, with a specified direction or causal flow (Hayes, 2013, p. 114)—such that the association between dieting and weight gain is mediated by a causal chain where emotional eating predicts external eating, and where external eating, in turn, predicts weight gain. The expected serial chain would then read as follows: dieting $\rightarrow$ emotional eating $\rightarrow$ external eating $\rightarrow$ weight gain. This serial mediation can be explained as follows. Emotional eating tends to co-occur with external eating $(r=.50)$ (Van Strien, 2015). According to the escape theory of Heatherton and Baumeister (1991), some individuals may narrow their level of attention to the current and immediate stimulus environment (accessible food cues such as snacks), in order to shift their attention away from negative affect, like depression. Applied to the current context, the co-occurrence of emotional and external eating can be explained by the possibility that some people, (e.g. emotional eaters) may shift their attention away from their negative affect by narrowing it to the immediate (food) environment with external eating as a result. In support, Slochower (1983) showed in an experiment that negative emotions and food cues operate conjointly to elicit overeating in female students with obesity-the obese participants only overate in the high anxiety-high food salience condition, but not when the anxiety and/or the food salience was low. A functional neuro-imaging study in female chronic dieters additionally showed that negative affect was associated with an increase in the reward value of appetizing food cues (Wagner, Boswell, Kelley \& Heatherton, 2012), which increase was in a further study found to predict weight gain six months later (Demos, Heatherton, \& Kelley, 2012). Increased brain response to food-cues and selective attention to food cues after negative mood were further found to be associated with the self-reported eating

\footnotetext{
${ }^{1}$ While acknowledging that dieting may be a proxy for susceptibility to weight gain, because of pre-existing other factors, such as pre-exiting tendencies towards emotional and external eating (Van Strien, 2018), or genetic susceptibility (Pietiläinen et al., 2012), dieting may also have an independent effect on subsequent weight gain. This latter position is taken in the present study.
}

styles emotional and external eating (Bloemendaal et al., 2015; Hepworth, Mogg, Brignell \& Bradley, 2010). In a prospective study on Korean twins and their families, external eating, in turn, was significantly associated with a recent increase in BMI (Sung, Lee \& Song, 2014; but see for negative evidence,; Sung et al., 2009; Koenders \& Van Strien, 2011).

Emotional eating and external eating were examined as possible mediators between dieting and weight gain (change in body mass index (BMI)) in a series of studies on women. Models examined whether emotional eating solely mediated the relationship between dieting and weight gain and whether emotional eating and external eating serially mediated the relationship between dieting and weight gain. In a pilot study on female students, we first assessed these mediations between frequency of dieting or dietary restraint and actual food consumption in the laboratory. In Study 1, a re-analysis of data from a four-year follow up on female patients with newly diagnosed type 2 diabetes mellitus, we assessed these mediations between dietary restraint and change in BMI and intake of energy. In Study 2, a re-analysis of data from a threeyear follow up study in the women of the representative Dutch sample, we assessed these mediations between frequency of dieting and change in BMI.

\section{The pilot study}

\subsection{Rationale and aim}

Before analyzing the longitudinal studies with change in BMI as the main outcome variable, we first assessed in a pilot study the serial mediation of emotional and external eating between dieting and actual food intake: dieting $\rightarrow$ emotional eating $\rightarrow$ external eating $\rightarrow$ actual food intake.

For this pilot study, we re-analysed the data from a laboratory study by Ouwens, Van Strien and Van der Staak (2003), on the possible disinhibition effect of alcohol on food intake in dieters (e.g., Polivy \& Herman, 1976). This study had two conditions: the forced consumption of an alcoholic drink versus the consumption of a non-alcoholic drink. However, in the present pilot study the data from the two experimental conditions could be combined because there was no difference in food intake across the two conditions and there also was no interaction effect of condition with dietary restraint on food intake (see further: Ouwens et al., 2003).

It should be noted that in this pilot study no manipulation of emotion was used because the participation in an experiment in and out of itself may provoke the kind of anxiety that elicits overeating in emotional eaters (see for a similar kind of reasoning, Polivy \& Herman, 1976; Van Strien \& Ouwens, 2003 and its empirical evidence by Kaplan \& Hobart, 1965). It should further be noted that the assessment of dieting, emotional and external eating took place before the participants were subjected to the taste test (and their actual food intake). This made it possible to analyze the causal chain between dieting and food intake which causal chain to the best of our knowledge has not been studied yet. Dieting was measured with a question on frequency of dieting and a scale on dietary restraint.

\subsection{Participants and procedure}

The study was presented to the female participants as "a questionnaire investigation and alcohol-cracker taste test" (Ouwens et al., 2003). In this study all participants had filled out all questionnaires at recruitment, before the actual food intake. Women who drank 0 or more than 28 alcoholic units a week were excluded, therefore, though the participants were used to drinking alcohol they did not abuse alcohol. The study was performed according to the standards of ethical conduct and participants explicitly stated their informed consent by stating "Yes, I want to participate in an alcohol-cracker taste-test". After the experiment was over, the height and weight without shoes and with 
light clothing was measured; the participants in the alcohol condition were not allowed to leave the room before their blood alcohol concentration was below 0.50 promille.

In this experiment the participants were randomly assigned to an alcohol $(n=55)$ and a no-alcohol condition $(n=61)$, whereby they were instructed to completely finish a glass with $400 \mathrm{ml}$ alcohol-laced versus plain orange juice. After an absorption period of $20 \mathrm{~min}$ during which the participants watched fragments of the nature film Microcosmos (Nuridsany \& Perennou, 1996), they were presented three pre-weighed plates with savoury crackers with the instruction to taste the cookies and rate the flavours one by one. The mean BMI (body mass index; $\mathrm{kg} / \mathrm{m}^{2}$ ) of the 116 participants was 23.13 ( $\mathrm{SD}=2.92$; range $17.82-33.52$ ); the mean age was 21.08 ( $\mathrm{SD}=2.42$; range: $18-35$ years).

\subsection{Measures}

The Dutch Eating Behaviour Questionnaire (Van Strien, 2015; DEBQ; Van Strien, Frijters, Bergers, \& Defares, 1986) was used to assess emotional eating (13 items, e.g. "Do you have a desire to eat when you are irritated?"), external eating (10 items, e.g. "If food smells and looks good, do you eat more than usual?") and restrained eating (10 items, e.g. "Do you try to eat less at mealtimes than you would like to eat?"). Response categories range from 1 'never' to 5 'very often'. The three scales have good reliability, dimensional validity (Barrada, Van Strien, \& Cebolla, 2016) and predictive validity for, respectively, distress induced food intake (Domoff, Meers, Koball, \& Musher-Eizenman, 2014; Oliver, Wardle \& Gibson, 2000; Van Strien et al., 2013; Van Strien, Herman, Anschutz, Engels, \& de Weerth, 2012), eating in response to food cues (Van Strien, Herman, \& Anschutz, 2012) and eating less than desired (Van Strien, Engels, van Staveren, \& Herman, 2006; Van Strien \& Van de Laar, 2008). The DEBQ has been rated as 'up to the mark' or 'good' by the Dutch Committee on Tests and Testing (COTAN) on all EFPA (European Federation of Psychologists' Association) criteria, e.g. norms, internal consistency, test-re-test reliability and dimensional, construct and criterion validity (COTAN, 2013). Table 1 shows the Cronbach's alpha of each of the three scales in the pilot study and study 1 and study 2 .

In addition to dietary restraint the effects of frequency of dieting were also assessed. This was done with the single item of the RS (Restraint Scale; Herman, Polivy, Pliner, Threlkeld, \& Munic, 1978): 'I diet' (never, rarely, sometimes, often, always) (See also: Keel, Baxter, Heatherton, \& Joiner, 2007).

Food intake was the sum of the grams of cookies eaten, they were savoury crackers (TUC from LU), in the flavors natural, paprika, and sesame.

\subsection{Confounders}

Experimental condition, baseline hunger, guessing the actual purpose of the experiment and BMI were treated as possible confounders. Baseline hunger was measured with a Visual Analogue Scale with at the extremes not at all and very much. The guessing of the actual purpose of the taste test was assessed in a final interview. A total of 33 participants $(28.4 \%)$ thought at the final interview that the amount of cookies

Table 1

Cronbach's alpha of restrained, emotional and external eating in the pilot study, study 1 , and study 2 .

\begin{tabular}{llll}
\hline & Pilot study & Study $1^{\text {a }}$ & Study 2 \\
\hline Restrained eating & 0.92 & 0.89 & 0.93 \\
Emotional eating & 0.90 & 0.89 & 0.95 \\
External eating & 0.76 & 0.79 & 0.81 \\
\hline
\end{tabular}

${ }^{\text {a }}$ Baseline. consumed would be counted.

\subsection{Analytic plan}

All analyses were carried out using SPSS version 23.0 (SPSS Inc., Chicago). The data were inspected for Skewness, Kurtosis and outliers ( $>3$ SD above or below the mean), but no problems were observed. Moreover, regression analyses are very robust for violations of normality (Hayes, 2013, p. 54), particularly so when using bootstrapping: "bootstrapping does not impose the assumption of normality of the sampling distribution" (Preacher \& Hays, 2008, p. 880). The Pearson correlations, means and standard deviations of the variables were calculated. With the PROCESS macro of SPSS, developed by Hayes (2013), we first assessed the serial mediation of emotional and external eating between frequency of dieting or dietary restraint and food intake (Model 6). This model assessed apart from serial mediation also the single mediation effects of emotional or external eating. We next assessed with PROCESS Model 4 the mediation effect of solely emotional eating (not controlling for external eating). In this approach, effects are assessed with bias-corrected accelerated bootstrap confidence intervals (CI) that are considered significant, respectively marginally significant, when the upper and lower bound of the bias-corrected 95\% CI, respectively, 90\% CI, does not contain zero. Bootstrapping with 5000 samples was used and analyses were controlled for possible confounders.

\subsection{Results}

Table 2 shows the correlation matrix involving the study variables. Food intake was significantly associated with emotional eating, external eating, baseline hunger and BMI, but not with dietary restraint, frequency of dieting, the experimental condition or whether the participants correctly had guessed the purpose of the study. Frequency of dieting and dietary restraint were highly correlated $(r=.72)$. Frequency of dieting and dietary restraint were both significantly associated with BMI and with emotional eating but not with external eating. Emotional and external eating were significantly associated $(r=.31)$.

\subsection{Serial mediation}

There was no overall significant association between frequency of dieting or dietary restraint and food intake (see Table 2). At present there is, however, agreement that mediation can exist and be tested even in the absence of such an overall significant association (see e.g. Kenny \& Judd, 2014; MacKinnon \& Fairchild, 2009). Therefore, analyses proceeded with the assessment of the (serial) mediation of emotional and external eating between dieting and food intake, adjusting for the four possible confounders: experimental condition, baseline hunger, guessing the actual purpose of the experiment and BMI.

First, the results regarding frequency of dieting are reported (Fig. 1 and Table 3). The total indirect effect (the difference between total and direct effect (c-c')) (not shown in Fig. 1) was not significant (B = 1.14; $95 \% \mathrm{CI}=-.41,3.07){ }^{2}$ In line with the hypothesis, the (non-total) indirect effect through emotional and external eating was significant $(\mathrm{B}=.55 ; 95 \% \mathrm{CI}=.14,1.50)$. The full model, containing dieting frequency, the two mediators and the confounders was also significant $(\mathrm{F}$ $(7,108)=5.05, \mathrm{p}<.001)$, and explained $25 \%$ of the variance in food intake. See Fig. 1, for the B ( $95 \%$ CI) associated with the various paths in the model. Highly similar results were obtained in the model without

\footnotetext{
${ }^{2}$ An insignificant total indirect effect can be explained by the possibility that one or two of the three indirect effects differed in sign from the other two or one indirect effects, so the sum of all indirect effects, which is the total indirect effect apparently summed up to zero (see Hayes, 2013, pp. 157-158). This was indeed the case in the present dataset.
} 
Table 2

Pearson correlations between the variables and the mean values (SDs) in the pilot study.

\begin{tabular}{|c|c|c|c|c|c|c|c|c|}
\hline & Food intake & Dieting frequency & Restrained eating & Emotional eating & External eating & Condition & Hunger & Check \\
\hline Food intake & 1 & & & & & & & \\
\hline Dieting frequency & -0.08 & 1 & & & & & & \\
\hline Restrained eating & -0.08 & $0.72 * * *$ & 1 & & & & & \\
\hline Emotional eating & $0.22^{*}$ & $0.25^{* *}$ & $0.18^{*}$ & 1 & & & & \\
\hline External eating & $0.40 * * *$ & 0.05 & 0.00 & $0.31^{* *}$ & 1 & & & \\
\hline Condition & 0.03 & 0.00 & 0.10 & 0.05 & -0.08 & 1 & & \\
\hline Hunger & $0.20^{*}$ & 0.12 & 0.10 & -0.01 & 0.09 & 0.06 & 1 & \\
\hline Check & 0.10 & -0.07 & -0.12 & 0.04 & -0.10 & 0.04 & 0.00 & 1 \\
\hline BMI & $-0.23 *$ & $0.30 * *$ & $0.34 * * *$ & 0.07 & -0.10 & -0.07 & -0.18 & 0.05 \\
\hline Mean & 39.5 & 1.1 & 2.6 & 2.7 & 3.1 & 0.5 & 62.0 & 1.7 \\
\hline SD & 20.2 & 1.1 & 0.7 & 0.6 & 0.5 & 0.5 & 20.5 & 0.5 \\
\hline
\end{tabular}

$\mathrm{SD}=$ standard deviation.

$* \mathrm{p}<.05 ; * * \mathrm{p}<.01 ; * * \mathrm{p}<.001$.

the four possible confounders. The (non-total) indirect effect through emotional and external eating was significant $(B=.54 ; 95 \% \mathrm{CI}=.12$, 1.34; explained variance: $18 \%$ ).

Highly similar results were obtained with dietary restraint (Fig. 1 and Table 3). The total indirect effect (c-c') (not shown in Fig. 1) was not significant $(\mathrm{B}=.82 ; 95 \% \mathrm{CI}=-1.42,3.27)^{2}$. In line with the hypothesis, the (non-total) indirect effect through emotional and external eating was significant $(B=.61 ; 95 \% \mathrm{CI}=.12,1.79)$. The full model, containing dietary restraint, the two mediators and the confounders was significant $(\mathrm{F}(7,108)=4.99, \mathrm{p}<.001)$, and explained $24 \%$ of the variance in food intake. See Fig. 1, for the B (95\% CI) associated with the various paths in the model. Highly similar results were obtained in the model without the four possible confounders. The (non-total) indirect effect through emotional and external eating was significant $(\mathrm{B}=.56 ; 95 \% \mathrm{CI}=.11,1.59$; explained variance: $18 \%)$.

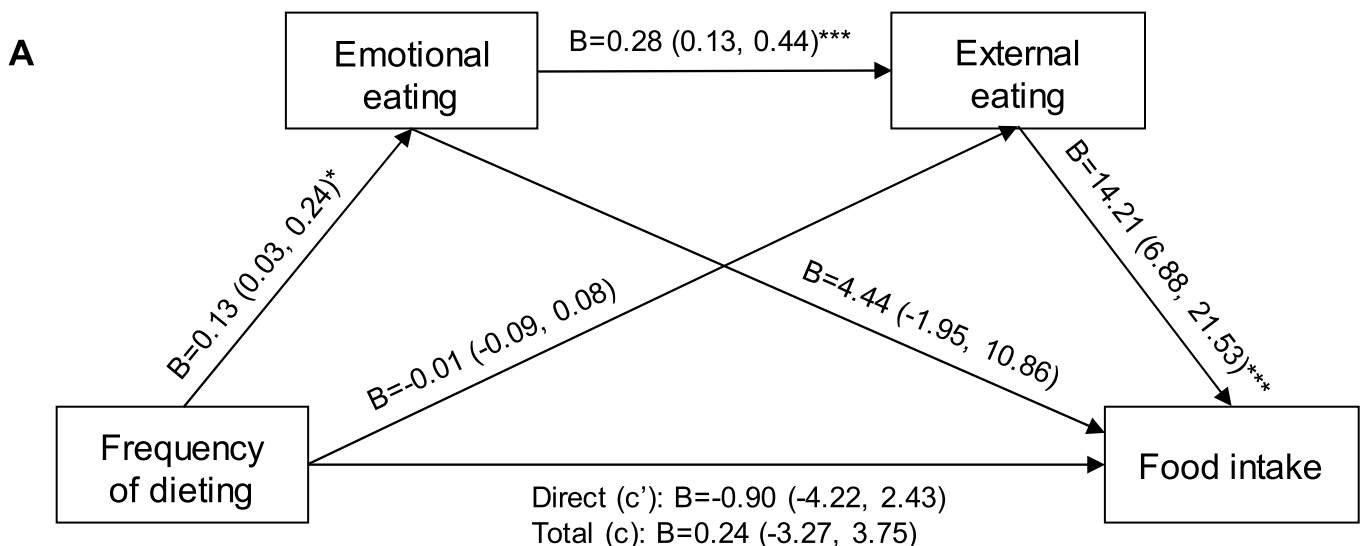

Total $(c): B=0.24(-3.27,3.75)$

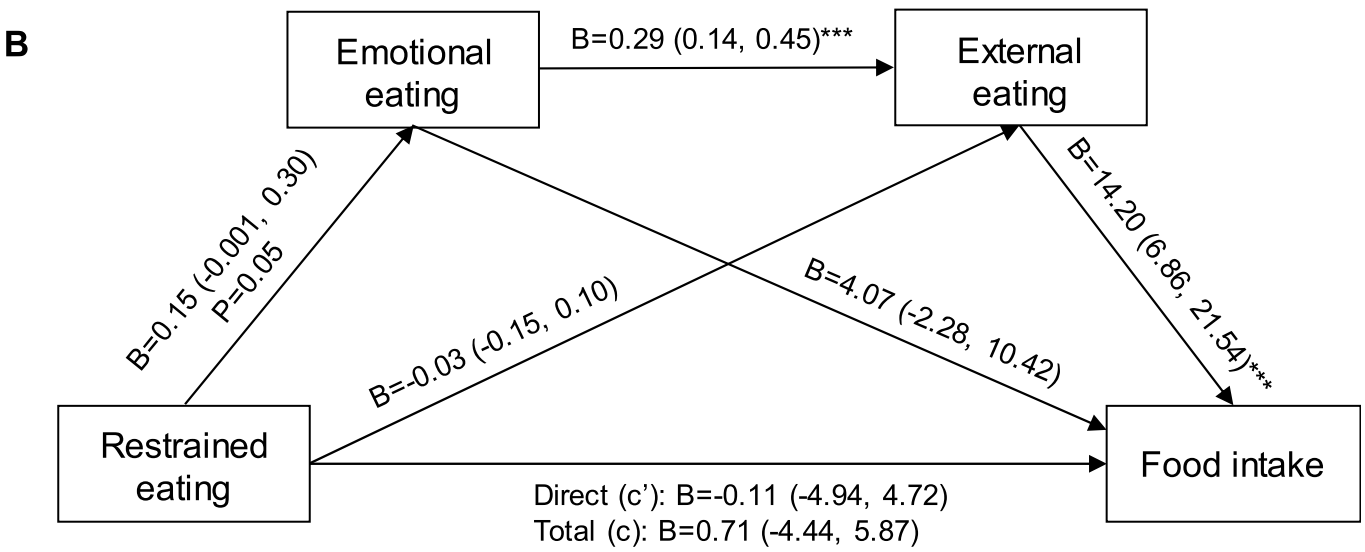

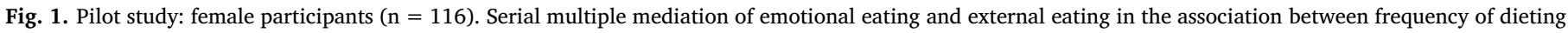

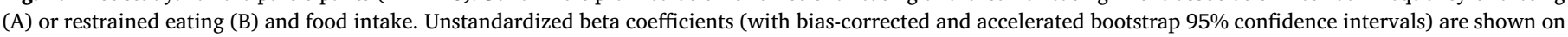

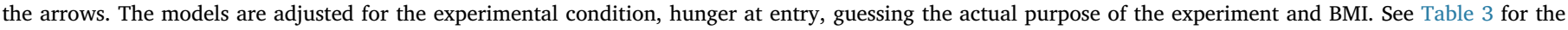
indirect effects of dieting frequency and restrained eating on food intake. ${ }^{*} \mathrm{p}<.05$, ${ }^{* * \mathrm{p}}<.01$, and ${ }^{* * * \mathrm{p}}<.001$. 


\subsection{Single mediation}

When testing a single mediation model with solely emotional eating (not controlling for external eating) the indirect of emotional eating was significant for both frequency of dieting and dietary restraint (indirect effect: $\mathrm{B}=1.15 ; 95 \% \mathrm{CI}=0.22,2.88$, respectively, $\mathrm{B}=1.22$; $95 \% \mathrm{CI}=0.12,3.41$ ). The full model containing frequency of dieting or dietary restraint, respectively, the mediator emotional eating and the confounders was in both cases significant $(\mathrm{F}(6,109)=3.05, \mathrm{p}=.009$, respectively $\mathrm{F}(6,109)=3.006), \mathrm{p}=.009)$ and explained in both cases $14 \%$ of the variance in food intake.

When comparing the explained variance in food intake of the single mediation model with that of the serial mediation model, the single mediation model explained, however, less variance in food intake than the serial mediation model.

\subsection{Summary and conclusion of the pilot study}

Frequency of dieting and dietary restraint were not directly associated with food intake. Instead they were indirectly associated through a serial chain where frequency of dieting and dietary restraint predicted emotional eating, which in turn predicted external eating which in turn predicted food intake. The fact that the assessment of frequency of dieting, dietary restraint, emotional eating and external eating all took place before the taste test study (and the actual food intake), is a strength of the study, but a weakness is that frequency of dieting, dietary restraint and the eating styles emotional and external eating were all simultaneously assessed in one questionnaire. Theoretically it is possible that emotional and external eating preceded frequency of dieting/dietary restraint, in turn predicting food intake. However a prerequisite for such a causal chain is that frequency of dieting/dietary restraint would be associated with food intake, which was not the case in the present dataset.

In conclusion: The present study provided support for a serial chain where frequency of dieting and dietary restraint predicted emotional eating, which in turn predicted external eating which in turn predicted food intake. However, because the assessment of frequency of dieting/ dietary restraint did not take place in time before the assessment of emotional and external eating, this serial chain is in need of replication in a longitudinal study, preferably one in which this requirement is met.

\section{Study 1}

Study 1 is a re-analysis of a 4-year follow-up study among patients with newly diagnosed Type 2 diabetes. Patients were assessed at diagnoses (baseline), after they had received dietary advice from a registered dietician according to the current guidelines (8 weeks), and after (on average) 4 years (Van de Laar et al., 2006; Van Strien et al., 2007; Van Strien \& van de Laar, 2008). Dietary restraint, emotional eating and external eating were assessed at baseline. Therefore, like in the pilot study, dietary restraint and emotional and external eating were simultaneously assessed. Unlike in the pilot study, the outcome measures were change in BMI (assessed by the physician) and energy intake as measured with a Food Frequency Questionnaire (FFQ) four years after diagnosis. The FFQ uses the past month as a reference period, which meets the requirement of valid dietary assessment where a minimum time window of $24 \mathrm{~h}$ is required (Stubbs, Jonstone, Reilly \& Poppitt, 1998). Earlier analyses in the dataset with both sexes combined showed that the combination of emotional and external eating and not dietary restraint predicted BMI gain and energy intake at follow-up (Van Strien et al., 2007). The results for only the women are unknown. The present study assessed in the (sub) sample of women the (serial) mediation of emotional and external eating between dietary restraint and BMI gain, and between dietary restraint and intake of energy after 4 years. This (serial) mediation has not been studied yet. 


\subsection{Participants and procedure}

The patients with newly diagnosed Type 2 diabetes (aged 40-70 years) were obtained from Dutch general practices. Complete information on recruitment and patients' characteristics is provided elsewhere (Van de Laar et al., 2006; Van Strien et al., 2007). ${ }^{3}$ For the present study, complete data on the relevant variables were available for 51 women. The study was performed according to the standards of ethical conduct, and all patients gave written informed consent. The study protocol was approved by the Central Medical Committee for Studies in General Practice (first part) and the Local Ethics Committee of the Radboud University Nijmegen Medical Centre (4-year follow-up).

The mean age was 58.6 years $(\mathrm{SD}=8.1)$ and the mean $\mathrm{BMI}$ at baseline was $30.7(\mathrm{SD}=5.6)$. Thirty women $(59 \%)$ showed weight loss or maintenance of body weight after four years in relation to their body weight at diagnosis (mean weight loss $=-4.4 \mathrm{~kg}(\mathrm{SD}=3.8)$ ) and 21 women $(41 \%)$ showed weight gain in relation to their body weight at diagnosis (mean weight gain $=3.5 \mathrm{~kg}(\mathrm{SD}=2.0)$ ).

\subsection{Measurements}

Body mass index (BMI) at baseline and at 4-year follow up was based on measured body weight and height without shoes and with light clothing. In every practice, the same balance was used for subsequent measurements.

Intake of energy at 4-year follow up was measured with the Food Frequency Questionnaire (FFQ). In this questionnaire, the frequency of consumption of 104 food items is scored retrospectively, with as reference period one month (Meyboom, 1997). Intake of energy (MJ/day) was calculated using software especially designed for the questionnaire (Komeet, 2000). In the Leiden Longevity Study on 128 men and women, the intake of energy as assessed with the FFQ showed adequate agreement with the mean of three 24-h recalls (Crude Pearson's correlation coefficient: 0.55). (Streppel et al., 2013).

Dietary restraint, emotional and external eating at baseline and at 4year follow up (see the post hoc analyses) were measured with the DEBQ (see the pilot study and see Table 1 for the Cronbach's alpha of the scales in Study 1).

\subsection{Possible confounders}

The same confounders as in the study by Van Strien et al., 2007 were used. Specifically, in the analyses with change in BMI as dependent variable $(\mathrm{Y}$ ), this was smoking at follow up ("Do you smoke: yes/ no"); in the analyses with intake of energy as dependent variable (Y) this was body weight at follow up (measured body weight) and physical activity at follow up (as assessed with nine yes/no questions developed by Caspersen, Bloemberg, Saris, Merritt, \& Kromhout, 1991), because energy requirement depends on body weight and physical activity.

\footnotetext{
3 "We used data from a prospective cohort study, in which patients with newly diagnosed Type 2 diabetes (aged 40-70 years) were included from 33 general practices throughout the Netherlands $(n=144)$. Our primary aim was to assess alterations in energy and fat intake (see Van de Laar et al., 2004). Patients $(n=106)$ answered follow-up questions 4 years after the initial study. Reasons for missing data on energy and fat intake were that the patients died ( $n=8)$, moved to an unknown address $(n=4)$, had another reason or an unknown reason for not responding $(n=5)$, or refused to fill out the food frequency questionnaire $(n=21)$. However, 3 of those patients still provided data on body weight and eating behavior. For the present study, complete data on body weight and energy intake at follow-up (the dependent variables in this study) were available for 46 men and 51 women. Relevant baseline characteristics of those who did not participate at the 4-year follow-up did not differ significantly from the subjects whose 4-year measurements were not missing." (Van Strien et al., 2007, p. 106).
}

\subsection{Analytic plan}

We used the same analytic plan as in the pilot study. As in the pilot study, effects of (serial) mediation are assessed with bias-corrected accelerated bootstrap confidence intervals (CI) that are considered significant, respectively marginally significant, when the upper and lower bound of the bias-corrected 95\% CI, respectively, 90\% CI, does not contain zero.

\subsection{Results}

Change in BMI was calculated by regressing BMI at follow up on BMI at baseline. There were no problems with Skewness and Kurtosis. Table 4 shows the correlation matrix involving the variables in the study.

Restrained eating was significantly associated with emotional eating, in turn significantly associated with external eating, in turn significantly associated with change in BMI. Intake of energy was significantly associated with emotional eating but not with external eating. Emotional eating and external eating were both significantly associated with body weight at follow up. Smoking at follow up was associated with change in BMI.

\subsection{Serial mediation}

The results for the serial mediation analysis with change in BMI as dependent variable are reported first (Fig. 2 and Table 3). The total indirect effect (the difference between total and direct effect (c-c')) (not shown in Fig. 2) was not significant $(B=.03 ; 95 \% C I=-.13,0.19)^{2}$. In line with the hypothesis, the indirect effect through emotional and external eating was significant $(B=.06 ; 95 \% \mathrm{CI}=.01,0.19)$. The full model, containing restrained eating, the two mediators and the confounder smoking was significant $(\mathrm{F}(4,46)=3.67, \mathrm{p}=.011)$, and explained $24 \%$ of the variance in change in BMI. See Fig. 2, for the B $(95 \%$ CI) associated with the various paths in the model.

When testing a single mediation model with solely emotional eating, the indirect effect of emotional eating was not significant at $95 \%$ $\mathrm{CI}$ or $90 \% \mathrm{CI}$ (indirect effect: $\mathrm{B}=-0.03$; $95 \% \mathrm{CI}=-0.21,0.04$ ).

The results with intake of energy at follow up as dependent variable are reported next (Fig. 2 and Table 3). Not shown in Fig. 2, the total indirect effect (c-c') was significant $(B=375.92 ; 95 \%$ CI $=57.86$, 1136.07), and though there was a significant indirect effect through emotional eating $(B=219.73$; $95 \% \mathrm{CI}=5.79,717.21$ ), the serial chain through emotional and external eating was marginally significant ( $\mathrm{B}=84.33 ; 90 \% \mathrm{CI}=3.78,402.39$ ). The full model, containing restrained eating, the two mediators and the confounders was significant $(\mathrm{F}(5,45)=3.47, p<.01)$ and explained $28 \%$ of the variance in intake of energy. See Fig. 2, for the B (95\% CI) associated with the various paths in the model.

For comparison: When a single mediation model with emotional eating as the only mediator (Model 4) was tested, the indirect effect of restrained eating on intake of energy through emotional eating remained significant ( $\mathrm{B}=304.06 ; 95 \% \mathrm{CI}=46.62$, 897.10). The full model containing restrained eating, the mediator emotional eating and the confounders was significant $(\mathrm{F}(4,46)=3.39, p=.016)$, and explained $23 \%$ of the variance in intake of energy.

Highly similar results were obtained when all above analyses were replicated without the possible confounders.

\subsection{Post hoc analyses}

A limitation of study 1 is that restrained eating, emotional and external eating were simultaneously measured with one questionnaire at baseline. Therefore we searched for additional support of this specific serial causal chain (restrained eating predicting emotional eating predicting external eating predicting change in BMI or food intake at 
follow up) by conducting a series of post-hoc analyses. In these analyses we tested the following serial mediation through emotional eating and external eating, as measured at follow up (after four years): Baseline dietary restraint $\rightarrow$ emotional eating at follow up $\rightarrow$ external eating at follow up $\rightarrow$ change in BMI or food intake at follow up.

Table 4 shows between brackets the Pearson correlations of emotional and external eating at follow up with the other study variables. The results on the post hoc serial mediation analyses with change in BMI and food intake at follow up are shown in Fig. 2 [between brackets] and in Table 3. As can be seen in the tables and the Figure, results went in the same direction as those of the earlier (not post-hoc) analyses. Specifically: Baseline dietary restraint was found to be significantly associated with subsequent change in BMI through subsequent emotional and external eating $(B=.07 ; 95 \% \mathrm{CI}=.01,0.23)$. There was no support for a mediation effect of solely emotional eating at $95 \% \mathrm{CI}$ or $90 \% \mathrm{CI}$ (indirect effect: $\mathrm{B}=-0.02 ; 95 \% \mathrm{CI}=-0.18$, 0.08). Further, though there was no significant or marginally significant serial mediation of subsequent emotional and external eating between baseline dietary restraint and intake of energy at follow up, there was a marginally significant mediation effect of subsequent emotional eating between baseline dietary restraint and intake of energy at follow up (B $=231.15 ; 90 \% \mathrm{CI}=19.12,606.30)$.

\subsection{Summary and conclusion of study 1}

In the female patients with newly diagnosed type 2 diabetes, dietary restraint was not directly associated with either change in BMI or intake of energy after 4 years. Instead they were indirectly associated through a chain of associations where dietary restraint was associated with emotional eating, which in turn predicted external eating which in turn predicted change in BMI after four years (95\% CI). Results for intake of energy after four years went in the same direction, but were only significant at the $90 \%$ CI. A single mediation model with emotional eating as the mediator was significant at the $95 \% \mathrm{CI}$, but this model predicted somewhat less variance in food intake $(23 \%)$ than the serial mediation model which predicted $28 \%$ of the variance in intake of energy. Additional support for (serial) mediation of emotional eating (and external eating) was provided by the results of the post hoc analyses, where we tested the (serial) mediation of emotional and external eating at the follow up (after four years).

A strength of study 1 is the longitudinal design with a 4-year followup, in a cohort of patients in which a high motivation for weight loss can be assumed (since they were newly diagnosed with type 2 diabetes, and weight loss is one of the main treatment targets). A further strength was that the study was rooted in the general practice of GP's, which means that the study environment corresponds with daily life, and that the variable change in BMI was based on measured weight and height (instead of self-reported weight and height).

A limitation is that the method of measuring food intake (with the FFQ) may be subject to recall bias. However, as already argued in Van Strien et al. (2007) a real gold standard for measurement of food intake does not exist. All ways to measure food intake are subject to recall bias or reactivity (as is the case with record keeping or self-monitoring). The 'unobtrusive' measurement of food intake in a so called taste test (as in the pilot study), is at variance with the guidelines for assessment of chronic dietary intake, where a minimum time window of $24 \mathrm{~h}$ is recommended (Stubbs et al., 1998).

Finally, though the present study aimed to test the indirect effect of dietary restraint on subsequent change in body weight and intake of energy it cannot be ruled out that overeating tendency preceded subsequent dietary restraint and change in BMI or intake of energy whilst it is also possible that they are reciprocally related. (Van Strien et al., 2007; Van Strien, 1996; 1999). Therefore, the present results are in need of replication in a further prospective study. 
A

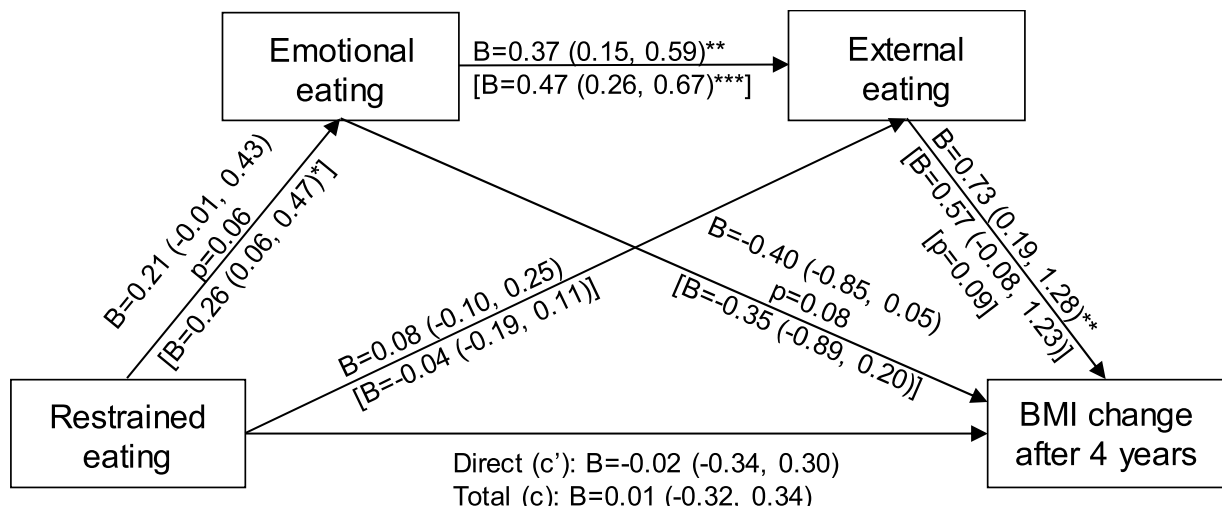

Total (c): $B=0.01(-0.32,0.34)$

[Direct (c'): $B=0.05(-0.29,0.40)$ ]

[Total (c): $B=0.01(-0.32,0.34)]$
Fig. 2. Study 1: female patients with newly diagnosed type 2 diabetes $(n=51)$. Serial multiple mediation of emotional eating and external eating at baseline and at follow up [] in the association between restrained eating and BMI change (A) or food intake (B) after 4 years. Unstandardized beta coefficients (with bias-corrected and accelerated bootstrap 95\% confidence intervals) are shown on the arrows. The model for BMI change is adjusted for smoking at 4 years and the model for food intake is adjusted for body weight and physical activity at 4 years. See Table 3 for the indirect effects of restrained eating on BMI change and food intake after 4 years. * $\mathrm{p}<.05$, $* * \mathrm{p}<.01$, and $* * * \mathrm{p}<.001$.

B

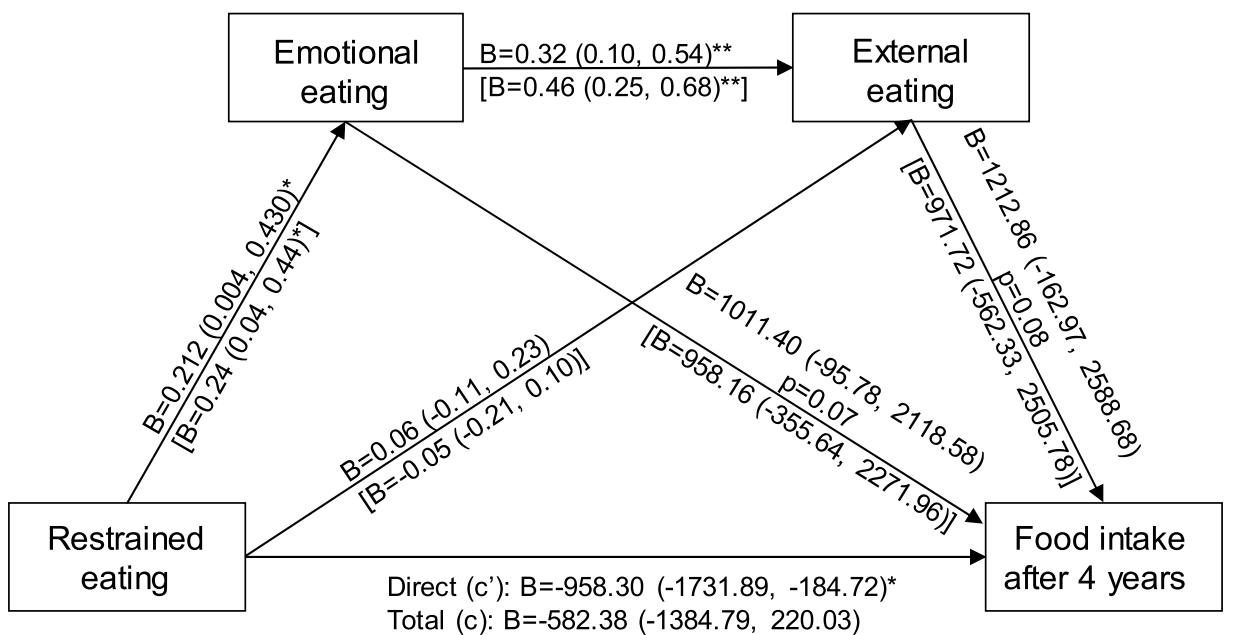

[Direct (c'): $\left.B=-863.45(-1675.39,-50.51)^{\star}\right]$

[Total (c): $B=-573.22(-1385.51,239.07)]$

\section{Study 2}

Study 2 is a re-analysis of a 3-year follow-up study in a representative Dutch sample (Van Strien et al., 2014). In this study, dietary restraint and concern for dieting were associated with increases in BMI in the women but not in the men (Van Strien et al., 2014). Aim of the present study was to give possible explanations of the weight gain of the female dieters, by examining the underlying mechanisms (mediators) between dieting and weight gain in the women in this specific sample. Specifically, we wanted to test whether the association between frequency of dieting and BMI gain was serially mediated by emotional and external eating. This serial mediation model was examined in the entire sample of women. To be able to determine whether the results of the female patients with newly diagnosed Type 2 diabetes and overweight of Study 1 could be replicated in a Dutch sample with a similar degree of overweight, we also assessed the mediation models in the subsample of women with overweight.

A special feature of Study 2 is that frequency of dieting had been measured at baseline (autumn 2007), and emotional and external eating after 1.5 year (spring 2009), enabling a better assessment of the serial chain, as dieting frequency preceded emotional eating and external eating in real time of measurement.

\subsection{Participants and procedure}

Data were collected in a cohort of Dutch adults (representative for age, sex, level of education, ethnic origin and region in the Netherlands) as part of a larger longitudinal study on knowledge and use of a Dutch mass media campaign. Participants were recruited through a panel service agency. This agency invited the participants to fill out an online questionnaire and the collected data were treated conforming to the provisions of the Declaration of Helsinki. The study design is described more extensively elsewhere (Verheijden et al., 2012).

The data were collected either online, or using paper and pencil in a so called "food and health" study. The baseline measurement took place in November 2007. In spring 2009, the DEBQ with the scales on emotional and external eating was administered to the participants and three years after baseline (autumn 2010), the follow up of the present study took place.

After excluding participants with underweight at baseline or at follow up (BMI $\leq 17.5 \mathrm{~kg} / \mathrm{m}^{2}$ ), complete data were obtained from 287 women. The women had a mean age of 48.72 years $(S D=13.80)$; their mean BMI at baseline was $26.22 \mathrm{~kg} / \mathrm{m}^{2}(\mathrm{SD}=4.63)$, and their mean BMI at follow up was $26.88 \mathrm{~kg} / \mathrm{m}^{2}(\mathrm{SD}=5.01)$. A total of $146(50.9 \%)$ women had overweight at baseline. Their mean age was 47.28 years $(\mathrm{SD}=14.03)$, and their mean BMI at baseline was $29.57 \mathrm{~kg} / \mathrm{m}^{2}$ $(\mathrm{SD}=4.39)$.

\subsection{Measurements}

Frequency of dieting was measured at baseline (November 2007) with the single item "I diet" (never-always); emotional and external 
eating were measured with the DEBQ (Spring 2009); BMI at baseline (November 2007) and at follow up (autumn 2010) was calculated as self-reported weight $(\mathrm{kg})$ divided by self-reported height $(\mathrm{m})$ squared. Self-reported height and weight are considered reliable and valid for epidemiological studies (Stunkard \& Albaum, 1981).

\subsection{Confounders}

The variables that were earlier found to be associated $(\mathrm{p}<.10)$ with change in BMI in the entire sample (see Table 4, Van Strien et al., 2014) were treated as confounders, namely level of education, age group and physical activity. Level of education had three classes: $1=$ Lower (primary school, lower vocational or lower general secondary education); 2 = medium (intermediate vocational education, higher general secondary education or pre-university education); 3 = higher (higher vocational education or academic training). Agegroup had five levels: $1=18-29$ years; $2=30-39$ years; $3=40-55$ years; $4=56-64$ years; $5=65-75$ years. Physical activity was coded as 'not norm active' or 'norm active'. Norm active was defined as at least five days per week active for more than $30 \mathrm{~min}$ per day, in summer and winter (cycling, walking, doing sports or comparable moderately or intensive physical activities). Analyses could not control for smoking because smoking was not measured in the study.

\subsection{Results}

Change in BMI was calculated by regressing BMI at follow up on BMI at baseline. The same statistical analytic plan as in Study 1 was used. Serial mediation in the subsample of women with overweight was also assessed. Table 5 shows the correlations between the variables for the women and the overweight women [].

Frequency of dieting, emotional eating and external eating were positively associated with change in BMI. Frequency of dieting was positively associated with emotional eating but not with external eating. Emotional eating was highly correlated with external eating. In the overweight women (Table 5, between brackets []) a similar pattern of results was found. The only exception was that emotional eating was not significantly associated with change in BMI.

\subsection{Serial mediation}

In the entire sample of women the serial chain between frequency of dieting and change in BMI through emotional and external eating was not significant at the $95 \%$ CI $(-.012,0.027)$ or at the $90 \%$ CI $(-.009$, 0.023). A test of the single mediation through emotional eating was only significant at the $90 \% \mathrm{CI}(\mathrm{B}=.019 ; 90 \% \mathrm{CI}=.001,0.044)$. In the subsample of women with overweight (see Fig. 3 between brackets []), the serial chain between frequency of dieting and change in BMI through emotional and external eating was significant at the $95 \% \mathrm{CI}$ ( $\mathrm{B}=.0168 ; 95 \% \mathrm{CI}=.0002,0.0543)$. The full model, containing frequency of dieting, the two mediators and the three confounders was significant $(F(6,139)=3.52, p=.003)$, and explained $13 \%$ of the variance in change in BMI. There was no support for a mediation effect of solely emotional eating at $95 \%$ CI or $90 \%$ CI (indirect effect: $\mathrm{B}=0.01 ; 95 \% \mathrm{CI}=-0.01,0.04)$.

Highly similar results were obtained when the above analyses were replicated without the three possible confounders. There were the following exceptions: in the entire sample of women, the test of mediation through emotional eating was now significant at the $95 \% \mathrm{CI}(\mathrm{B}=.02$; $95 \% \mathrm{CI}=.01,0.05)$; in the women with overweight the B associated with the path from external eating to change in BMI was significant $(\mathrm{B}=.448 ; 95 \% \mathrm{CI}=.001,0.895 ; \mathrm{p}=.04)$.

\subsection{Summary and conclusion of study 2}

In the women of the prospective study in a representative Dutch

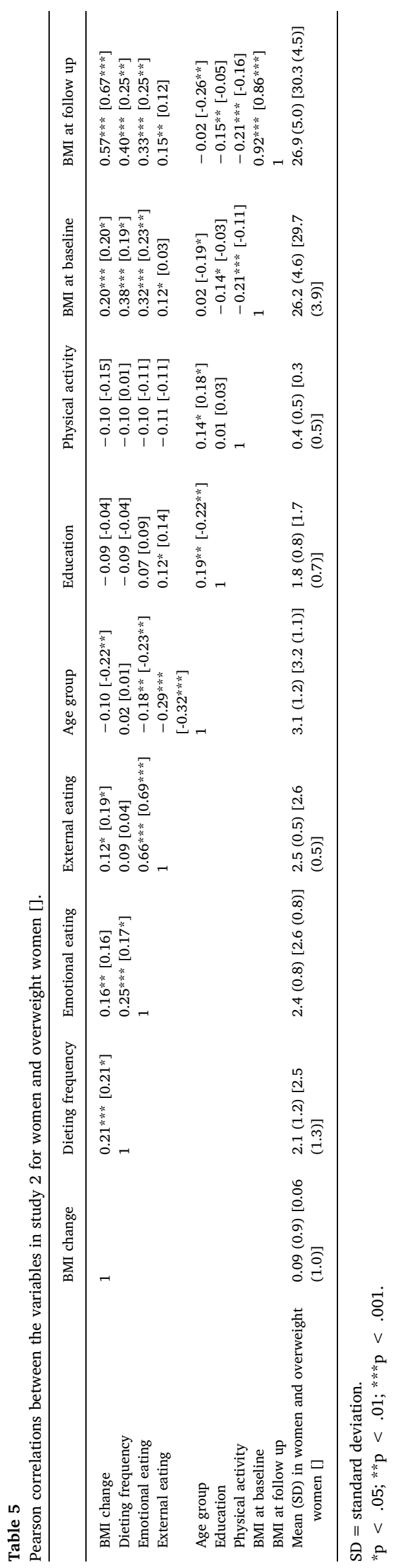




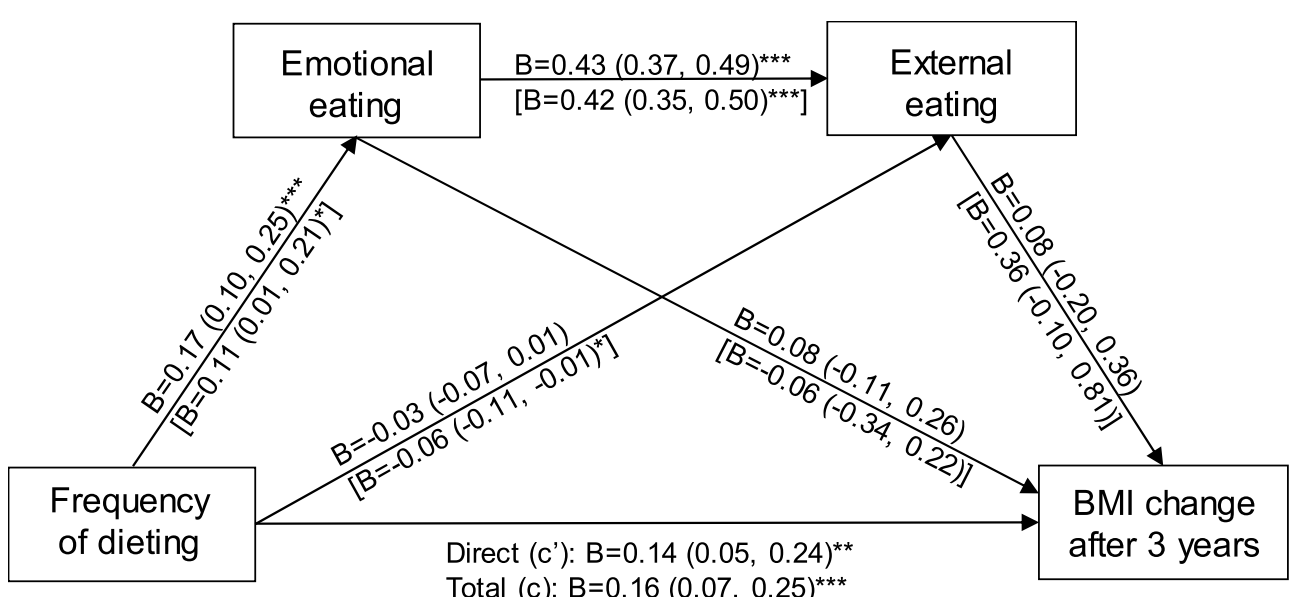

Total (c): $B=0.16(0.07,0.25)^{\star \star *}$

[Direct $\left(c^{\prime}\right): B=0.18(0.05,0.31)^{\star \star}$ ]

[Total $\left.(c): B=0.17(0.04,0.29)^{\star \star}\right]$
Fig. 3. Study 2: Women $(\mathrm{n}=287)$ and overweight women ( $\mathrm{n}=146$, between brackets []). Serial multiple mediation of emotional eating and external eating in the association between frequency of dieting and BMI change after 3 years. Unstandardized beta coefficients (with biascorrected and accelerated bootstrap 95\% confidence intervals) are shown on the arrows. The models are adjusted for age category, level of education and physical activity. See Table 3 for the indirect effects of dieting frequency on BMI change after 3 years. ${ }^{*} \mathrm{p}<.05,{ }^{* *} \mathrm{p}<.01$, and $* * * \mathrm{p}<.001$. sample, support for this serial mediation model was only found in the subsample of women with overweight. In the entire sample of women there was instead some support for a (single) mediation model, namely a model where emotional eating acted as a mediator between frequency of dieting and change in BMI.

A strength of the study is large dataset, and the fact that the data were collected in a sample of people representative of the general population of The Netherlands. A further strength was that the assessment of frequency of dieting preceded the assessment of the mediators emotional eating and external eating in time, which, in turn, preceded the assessment of BMI after three years. However, emotional and external eating were simultaneously assessed, with one questionnaire (the DEBQ), therefore it is also possible that external eating preceded emotional eating.

A limitation was that all measures in this study were self-reported. The participants may, for example, have underestimated their body weight and overestimated their body length. However, this problem may be partly ruled out because of controlling for BMI at baseline when analyzing BMI at the 3-year follow up.

\subsection{General discussion}

To explain the often observed weight (re)gain of particularly female dieters, the present study assessed in various samples of women (one pilot study and two prospective studies) the possible (serial) mediation of emotional eating (and subsequent external eating) between dieting and change in BMI or food intake.

There was consistent evidence for the hypothesized (serial) mediation. Specifically: in the pilot study on female students, frequency of dieting and dietary restraint were both significantly indirectly associated with grams of crackers eaten through emotional and external eating. In the female participants of the 4-year prospective study on patients with newly diagnosed type 2 diabetes, dietary restraint had a significant indirect association with subsequent change in BMI (measured body weight and height) and a borderline (90\% CI) significant indirect association with intake of energy (Food Frequency Questionnaire) through emotional and external eating. In the overweight female participants of the 3-year prospective study in a representative Dutch sample, frequency of dieting was also indirectly associated with subsequent change in BMI (self-reported weight and height) through emotional and external eating. Only in the entire sample of female participants of the same prospective study, there was no evidence for serial mediation. Instead, there was only marginal $(90 \%$ CI) support for single mediation, in that emotional eating acted as a (single) mediator between frequency of dieting and subsequent change in BMI.

Taken together, the data suggest that dieting is associated with subsequent weight gain through emotional eating and external eating, or through solely emotional eating. However whether this (serial) mediation also implies that there is a causal chain that starts with dieting/dietary restraint cannot be determined from the present data. Even though the assessment of dieting in study 2 (the prospective study in a representative Dutch sample) preceded the assessment of emotional eating and external eating in real time, the dieting at the baseline of study 2 may have been a proxy for susceptibility to weight gain because of non-assessed pre-existing tendencies towards emotional and/or external eating. It is therefore not possible to resolve from the present data whether dieting or restrained eating is a cause or consequence of emotional eating (see Herman, Van Strien, \& Polivy, 2008; Polivy \& Herman, 1985; Van Strien, Herman \& Verheijden, 2012). It is also possible that this differs for various subgroups (Van Strien, Engels, Van Leeuwe, \& Snoek, 2005).

The present finding that the weight gain of dieters may be explained by emotional eating or the serial chain of emotional and external eating gives a possible explanation for the ineffectiveness of diets for permanent weight loss for many dieters on the long term. For the treatment of overweight this means that any tendencies towards emotional or external eating (irrespective whether they are cause or result of frequent dieting) should be assessed before an intervention is started, because these overeating tendencies were earlier shown to be inversely related to success and maintenance of weight loss (e.g., Elfhag \& Rössner, 2005). In the matched treatment approach suggested by Van Strien (2018), treatment of people with a high degree of emotional eating could focus on a more adequate response to negative emotions, for example by teaching emotion regulation skills. In a pilot study of a group dialectical behaviour therapy (DBT) adapted for obese emotional eaters, DBT appeared to be an effective intervention for reducing (eating related) pathology and body weight, also at the follow up (Roosen, Safer, Adler, Cebolla, \& Van Strien, 2012). There is also evidence that higher eating with awareness and higher eating without distraction is related to lower emotional and external eating (Winkens et al., 2018). ${ }^{4}$

\subsection{Strengths and limitations}

A strength of the study is that it consists of three studies that tackle

\footnotetext{
${ }^{4}$ Both mindful eating domains were recently found to be associated with change in depressive symptoms through serial mediation of emotional and external eating (Winkens et al., 2019, p. 208).
} 
the same research question with different datasets. In a pilot study the serial mediation model was piloted in an experiment on actual food intake in over 100 young adult women. The serial mediation model was subsequently tested in two prospective studies, one rooted in the general practice of GP's and conducted in patients with newly diagnosed type 2 diabetes and another in a representative Dutch sample. A limitation of all three studies is that frequency of dieting, dietary restraint and tendencies toward emotional and external eating were all self-reported, with possible over-reports of the tendency to diet and underreports of the tendency towards emotional and/or external eating. A limitation is that the BMI in the study on the representative Dutch sample was based on self-reported weight and height but a strength is that a highly similar result was obtained with measured BMI in the women of the study on patients with newly diagnosed type 2 diabetes. Finally, it should be noted that the tested mediation models explained around $20 \%$ of variance across the studies. This indicates that many other factors, not addressed in the present studies, influence food intake and change in body weight.

\section{Conclusion}

In conclusion, there was consistent evidence for (serial) mediation of emotional (and external eating) between dieting and change in BMI or food intake. This suggest that tendency toward emotional (and external eating) may explain the poor long-term success of diets for many dieters.

\section{Role of funding source}

Funding for Tatjana van Strien was provided by the European Union FP7 MooDFOOD Project 'Multi-country cOllaborative project on the rOle of Diet, FOod-related behavior, and Obesity in the prevention of Depression' (grant agreement no. 613598).

Funding for Hanna Konttinen was provided by the Academy of Finland (grants 314135 and 309157).

\section{Human and animal rights and informed consent}

This article contains studies/experiments with human subjects performed by the authors. All reported studies/experiments have been previously published and complied with all applicable ethical standards (including the Helsinki declaration and its amendments, institutional/ national research committee standards, and international/national/institutional guidelines).

\section{Declaration of competing interest}

Tatjana van Strien receives royalties for the DEBQ and its manual. The other authors declare no conflict of interest.

\section{Appendix A. Supplementary data}

Supplementary data to this article can be found online at https:// doi.org/10.1016/j.appet.2019.104493.

\section{References}

Almajwal, A. M. (2016). Stress, shift duty, and eating behavior among nurses in Central Saudi Arabia. Saudi Medical Journal, 37, 191-198. https://doi.org/10.15537/smj. 2016.2.13060.

Barrada, J. R., Van Strien, T., \& Cebolla, A. (2016). Internal structure and measurement invariance of the Dutch eating behavior questionnaire (DEBQ) in a (nearly) representative Dutch community sample. European Eating Disorders Review, 24(6), 503-509.

Bloemendaal, L. van, Veltman, D. J., ten Kulve, J. S., Drent, M. L., Barkhof, F., Diamant, M., et al. (2015). Emotional eating is associated with increased brain responses to food-cues and reduced sensitivity to GLP-1 receptor activation. Obesity, 23, 2075-2082. https://doi.org/10.1002/oby.21200.
Caspersen, C. J., Bloemberg, B. P. M., Saris, W. H. M., Merritt, R. K., \& Kromhout, D. (1991). The prevalence of selected physical activities and their relation with coronary heart disease risk factors in elderly men: The Zutphen study, 1985. American Journal of Epidemiology, 133, 1078-1092.

Chaput, J. P., Leblanc, C., Pérusse, L., Despès, J. P., Bouchard, C., \& Tremblay, A. (2009) Risk factors for adult overweight and obesity in the Quebec family Study. Have we been barking up the wrong tree? Obesity, 17, 1964-1970.

Beoordeling Nederlandse Vragenlijst voor Eetgedrag, NVECOTAN (2013). Review Dutch eating behaviour questionnaire (DEBQ, 2013). Retrieved from http://www. cotandocumentatie.nl/test_details.php?id $=848$.

Demos, K. E., Heatherton, T. F., \& Kelley, W. M. (2012). Individual differences in nucleus accumbens activity to food and sexual images predict weight gain and sexual behavior. Journal of Neuroscience, 32, 5549-5552.

Domoff, S. E., Meers, M. R., Koball, A. M., \& Musher-Eizenman, D. R. (2014). The validity of the Dutch eating behavior questionnaire: Some critical remarks. Eating and Weight Disorders-Studies on Anorexia, Bulimia and Obesity, 19(2), 137-144.

Drapeau, V., Provincer, V., Lemieux, S., Desprès, J. P., Bouchard, C., \& Tremblay, A. (2003). Do 6-y changes in eating behaviors predict changes in body weight? Results from the Québec family study. International Journal of Obesity, 27, 808-814.

Elfhag, K., \& Rössner, S. (2005). Who succeeds in maintaining weight loss? A conceptual review of factors associated with weight loss maintenance and regain. Obesity Reviews, 6, 67-85.

Field, A. E., Aneja, P., Austin, S. B., Shrier, L. A., de Moor, C., \& Gordon-Larsen, P. (2007). Race and gender differences in the association of dieting and gains in BMI among young adults. Obesity, 15, 456-464.

Frayn, M., \& Knäuper, B. (2018). Emotional eating and weight in adults: A review. Current Psychology, 37(4), 924-933. https://doi.org/10.1007/s12144-017-9577-9.

Gold, P. W., \& Chrousos, G. P. (2002). Organization of the stress system and its dysregulation in melancholic and a-typical depression. High vs low CRH/NE states. Molecular Psychiatry, 7, 254-275.

Goldsmith, R., Joanisse, D., Gallagher, D., Pavlov, K., Shamoon, E., Leibel, R. L., et al. (2010). Effects of experimental weight perturbation on skeletal work efficiency, fuel utilization, and biochemistry in human subjects. American Journal of Physiology Regulatory, Integrative and Comparative Physiology, 298, R79-R88.

Hayes, A. F. (2013). Introduction to mediation, moderation and conditional process analysis. New York: Guilford Press.

Heatherton, T. F., \& Baumeister, R. F. (1991). Binge eating as escape from self-awareness Psychological Bulletin, 110, 86-108.

Heatherton, T. F., Herman, C. P., \& Polivy, J. (1991). Effects of physical threat and ego threat on eating behavior. Journal of Personality and Social Psychology, 60, 138-143.

Hebworth, R., Mogg, K., Brignell, C., \& Bradley, B. P. (2010). Negative mood increases selective attention to food cues and subjective appetite. Appetite, 54, 134-142. https://doi.org/10.1016/j.appet.2009.09.019.

Herman, C. P., \& Polivy, J. (1975). Anxiety, restraint and eating behavior. Journal of Abnormal Psychology, 84, 666-672.

Herman, C. P., \& Polivy, J. (1980). Restrained eating. In A. J. Stunkard (Ed.). Obesity (pp. 208-225). Philadelphia: W.B. Saunders.

Herman, C. P., Polivy, J., Pliner, P., Threlkeld, J., \& Munic, D. (1978). Distractibility in dieters and nondieters. An alternative view of "externality". Journal of Personality and Social Psychology, 36, 536-548.

Herman, C. P., Van Strien, T., \& Polivy, J. (2008). Undereating or eliminating overeating? American Psychologist, 63, 202-203.

Kaplan, S., \& Hobart, J. L. (1965). New technique for recording skin resistance. The American Journal of Medical Electronics, 4, 117-120.

Keel, P. K., Baxter, M. G., Heatherton, T. F., \& Joiner, T. F. (2007). A 20-year longitudinal study of body weight, dieting and eating disorder symptoms. Journal of Abnormal Psychology, 116, 422-432.

Kenny, D., \& Judd, C. (2014). Power anomalies in testing mediation. Psychological Science, 25(2), 334.

Klesges, R. C., Isbell, T. R., \& Klesges, L. M. (1992). Relationship between dietary restraint, energy intake, physical activity, and body weight. A prospective analysis. Journal of Abnormal Psychology, 101(4), 668-674.

Koenders, P., \& Van Strien, T. (2011). Emotional eating rather than lifestyle behaviour drives weight gain in a prospective study in 1562 employees. Journal of Occupational and Environmental Medicine, 53, 1287-1293.

Komeet (2000). Computer software. Arnhem, the Netherlands: BaS Nutrition Software Version 3.0.

Korkeila, M., Rissanen, A., Kaprio, J., Sørensen, T. I. A., \& Koskenvuo, M. (1999). Weightloss attempts and risk of major weight gain: A prospective study in Finnish adults. American Journal of Clinical Nutrition, 70, 965-975.

Langeveld, M., \& DeVries, H. (2015). The long-term effect of energy restricted diets for treating obesity. Obesity, 23, 1529-1538. https://doi.org/10.1002/oby.21146.

MacKinnon, D. P., \& Fairchild, A. J. (2009). Current directions in mediation analysis. Current Directions in Psychological Science, 18, 16-20.

Mann, T., Tomiyama, J., Wesling, E., Lew, A., Samuels, B., \& Chatman, J. (2007). Medicare's search for effective obesity treatments. Diets are not the answer. American Psychologist, 62, 220-233.

Meyboom, S. (1997). Voedselvragenlijst naar de vetconsumptie [Food Frequency Questionnaire]. Wageningen, the Netherlands: Wageningen University Unpublished manuscript.

Nakamura, Y., Walker, B. R., \& Ikuta, T. (2016). Systematic review and meta-analysis reveals acutely elevated plasma cortisol following fasting but not less severe calorie restriction. Stress, 19(2), 151-157. https://doi.org/10.3109/10253890.2015. 1121984.

Nuridsany, C., Pérennou, M., Films, G., Perrin, J., Barratier, C., et al. (1996). Microcosmos [film]. Miramax. 
Oliver, G., Wardle, J., \& Gibson, E. L. (2000). Stress and food choice: A laboratory study. Psychosomatic Medicine, 62, 853-865.

Ouwens, M. A., Van Strien, T., \& Van der Staak, C. P. F. (2003). Absence of a disinhibition effect of alcohol on food consumption. Eating Behaviors, 4, 323-332.

Piëtiläinen, K. H., Saarni, S. E., Kaprio, J., \& Rissanen, A. (2012). Does dieting make you fat? A twin study. International Journal of Obesity, 36, 456-464.

Polivy, J., \& Herman, C. P. (1976). Effects of alcohol on eating behavior: Influence of mood and perceived intoxication. Journal of Abnormal Psychology, 85(6), 601-606. https://doi.org/10.1037/0021-843X.85.6.601.

Polivy, J., \& Herman, C. P. (1985). Dieting and bingeing. A causal analysis. American Psychologist, 40(2), 193-201.

Preacher, K. J., \& Hayes, A. (2008). Asymptotic and resampling strategies for assessing and comparing indirect effects in multiple mediator models. Behavior Research Methods, 40, 879-891.

Rodin, J. (1981). Current status of the internal-external hypothesis for obesity. What went wrong. American Psychologist, 36, 361-372.

Roosen, M. A., Safer, D. L., Adler, S., Cebolla, A., \& Van Strien, T. (2012). Group dialectical therapy adapted for obese emotional eaters: A pilot study. Nutricion Hospitalaria, 27, 1125-1131.

Sares-Jäske, L., Knekt, P., Männistö, S., Lindfors, O., \& Heliövaara (2019). Self-report dieting and long-term changes in body mass index and weight circumference. Obesity Science and Practice. https://doi.org/10.1002/osp4.336.

Siahpush, M., Tibbits, M., Shaikh, R. A., Singh, H. G. K., Kessler, A. S., \& Huang, T. K. (2015). Dieting increases the likelihood of subsequent obesity and BMI gain: Results from a prospective study of an Australian national sample. International Journal of Behavioural Medicine, 22, 662-671.

Slochower, J. A. (1983). Excessive eating. The role of emotions and the environment. New York: Human sciences press, Inc.

Streppel, M. T., de Vries, J. H. M., Meijboom, S., Beekman, M., de Craen, A. J. M., Slagboom, P. E., et al. (2013). Relative validity of the food frequency questionnaire used to assess dietary intake in the Leiden longevity study. Nutrition Journal, 12, 75.

Stubbs, R. J., Johnstone, A. M., O'Reilly, L. M., \& Poppitt, S. D. (1998). Methodological issues relating to the measurement of food, energy and nutrient intake in human laboratory-based studies. Proceedings of the Nutrition Society, 57, 357-372.

Stunkard, A. J., \& Albaum, J. M. (1981). The accuracy of self-reported weights. American Journal of Clinical Nutrition, 34, 1593-1599.

Sung, J., Lee, K., \& Song, Y. (2009). Relationship of eating behaviour to long-term weight change and body mass index. The healthy twin study. Eating and Weight Disorders, 14, e98-e105.

Sung, J., Lee, K., \& Song, Y. (2014). Dietary restraint is non-genetically associated with change in body mass index: The healthy twin study. Yonsei Medical Journal, 55, 1138-1144.

Van Strien, T. (1996). On the relationship between dieting and obese and bulimic eating patterns. International Journal of Eating Disorders, 19, 83-92.

Van Strien, T. (1999). Success and failure in the measurement of restraint: Notes and data. International Journal of Eating Disorders, 25, 441-449.

Van Strien, T. (2015). Nederlandse Vragenlijst voor eetgedrag (NVE). Handleiding. [Dutch eating behaviour questionnaire]. Manual. Amsterdam: Hogrefe.

Van Strien, T. (2018). Causes of emotional eating and matched treatment of obesity. Current Diabetes Reports, 18, 1-8. https://doi.org/10.1007/s11892-018-1000-x.

Van Strien, T., Cebolla, A., Etchemendy, E., Gutiërez-Maldonado, J., Ferrer-Garcia, M. Botella, C., et al. (2013). Emotional eating and food intake after sadness and joy. Appetite, 66, 20-25.
Van Strien, T., Donker, M. H., \& Ouwens, M. A. (2016). Is desire to eat in response to positive emotions an 'obese' eating style: Is Kummerspeck for some people a misnomer? Appetite, 100, 225-235.

Van Strien, T., Engels, R. C. M. E., Van Leeuwe, J., \& Snoek, H. M. (2005). The Stice model of overeating: Tests in clinical and non-clinical samples. Appetite, 45, 205-213.

Van Strien, T., Engels, R. C. M. E., Van Staveren, W., \& Herman, C. P. (2006). The validity of dietary restraint scales: Comment to Stice et al. Psychological Assessment, 18, 89-94.

Van Strien, T., Frijters, J. E. R., Bergers, G. P. A., \& Defares, P. B. (1986). The Dutch Eating Behaviour Questionnaire (DEBQ) for assessment of restrained, emotional and external eating behaviour. International Journal of Eating Disorders, 5, 295-315.

Van Strien, T., Herman, C. P., \& Anschutz, D. J. (2012a). The predictive validity of the DEBQ-external eating scale for eating in response to food commercials while watching television. International Journal of Eating Disorders, 45, 257-262.

Van Strien, T., Herman, C. P., Anschutz, D., Engels, R. C. M. E., \& de Weerth, C. (2012b). Moderation of distress-induced eating by emotional eating scores. Appetite, 58, $277-284$.

Van Strien, T., Herman, C. P., \& Verheijden, M. W. (2012c). Eating style, overeating and weight gain: A prospective 2-year follow-up study in a representative Dutch sample. Appetite, 59, 782-789.

Van Strien, T., Herman, C. P., \& Verheijden, M. W. (2014). Dietary restraint and body mass: A 3-year follow up study in a representative Dutch sample. Appetite, 76, 44-49.

Van Strien, T., \& Ouwens, M. A. (2003). Counterregulation in female obese emotional eaters: Schachter, Goldman, and Gordon's (1968) test of psychosomatic theory revisited. Eating Behaviors, 3, 329-340.

Van Strien, T., \& Van de Laar, F. (2008). Intake of energy is best predicted by overeating tendency and consumption of fat is best predicted by dietary restraint. A four-year follow up of patients with newly diagnosed type-2 diabetes. Appetite, 50, 544-547.

Van Strien, T., Van de Laar, F., Van Leeuwe, J. F. J., Lucassen, P. C. B., Van den Hoogen, H. J. M., \& van Weel, C. (2007). The dieting dilemma in patients with newly diagnosed type 2 diabetes: Does dietary restraint predict weight gain four years after diagnosis? Health Psychology, 26, 105-112.

Van de Laar, F. A., Van de Lisdonk, E. H., Lucassen, P. L. B. J., Stafleu, A., Mulder, J., Van den Hoogen, H. T. M., et al. (2006). Eating behavior and adherence to diet in patients with Type 2 diabetes mellitus. Diabetic Medicine, 23, 788-794.

Van de Laar, F. A., Van de Lisdonk, E. H., Lukassen, P. L. B. J., Tigchelaar, J. M. H., Meyboom, S., Mulder, L., et al. (2004). Fat intake in patients newly diagnosed with type 2 diabetes: A 4-year follow-up study in general practice. British Journal of General Practice, 54, 177-182.

Verheijden, M. W., van Dommelen, P., van Empelen, P., Crone, M. R., Wekmanm, A. M., \& van Kesteren, N. M. (2012). Changes in self-reported energy balance behaviours and body mass index during a mass media campaign. Family Practice, 29(Suppl. 1), i75-i81.

Wagner, D. D., Boswell, R. G., Kelley, W. M., \& Heatherton, T. F. (2012). Inducing negative affect increases the reward value of appetizing foods in dieters. Journal of Cognitive Neuroscience, 24, 1625-1633.

Winkens, L. H. H., Van Strien, T., Barrada, J. R., Brouwer, I. A., Penninx, B. W. J. H., \& Visser, M. (2018). The Mindful Eating Behavior Scale: Development and psychometric properties in a sample of Dutch adults aged 55 years and older. Journal of the Academy of Nutrition and Dietetics, 118(7), 1277-1290 e4.

Winkens, L. H. H., Van Strien, T., Brouwer, I. A., Penninx, B. W. J. H., \& Visser, M. (2019). Mindful eating and change in depressive symptoms: Mediation by psychological eating styles. Appetite, 133, 204-211. 